\title{
Comparing the Energy Consumption of Logistics Chains in Traditional Retailing and E-commerce for Popular Products in the Context of China
}

\author{
Wenjia Wang
}

\section{Abstract}

E-commerce has transformed the way in which people shop; and the introduction of modified logistics chains has profoundly influenced the retail industry. Changes in the logistic chains of e-commerce created uncertainty regarding the energy efficiency of this new business model. This paper compares the energy efficiency of logistics chains in China between traditional retailing and e-commerce models across a range of products that are mostly bought online. The results show that the percentage of airfreight used for transportation and the distribution distance in the e-commerce model has a strong influence on the overall energy efficiency of e-commerce logistics chains.

\section{Introduction}

In the past decade, information and communication technology (ICT), including the rise of online shopping, has fundamentally transformed people's lives. The convenience of online shopping and the variety of products available on the Internet have converted many store shoppers to home shoppers. According to a survey conducted by the Australian Communications and Media Authority (ACMA) regarding Australians' participation in e-commerce activities, 88 per cent of respondents performed at least one e-commerce activity in the past six months (ACMA 2010). In China, the number of online shoppers has reached 220 million (Redant n.d.).

With the proliferation of e-commerce, however, there is increased uncertainty regarding energy efficiency - in terms of the energy consumption incurred in the logistics chain for a purchase - in relation to the new business model. E-commerce is expected to influence a range of man-made systems of industrial 
infrastructure, including systems of manufacturing, transportation, packaging and warehousing (Abukhader 2003). For the retailing industry, the influence of ICT is profound. New logistics chains have been introduced into a model of e-commerce in which product and information flows will be significantly different from traditional retailing (Berger 2003).

This paper investigates the products most frequently purchased on the Internet and compares logistics chain energy consumption in traditional retailing and e-commerce models for retailing these products. Ideally, the methodology proposed in this paper will serve as a useful tool for the generalised study of the impacts of e-commerce on the retailing industry in terms of logistics chain energy consumption.

\section{Comparison Framework}

\section{Classification of Product Types}

According to the China Internet Network Information Centre (CNNIC) the most frequently purchased online merchandise in China is (in order of purchase frequency) (CNNIC 2013):

- clothing/shoes

- general merchandise

- computer equipment, communication devices and other digital products

- white goods

- books and audio-visual products

- health and beauty items

- groceries

Clearly these products vary from each other in terms of average size, weight and monetary value. Each of these features has an impact on the structure and energy consumption of the logistics chain during retailing. Thus the products are further categorised into 6 groups based on average size, weight and monetary value, as shown in Table 1. 
Table 1: Classification of Products Based on Product Type and Characteristics

\begin{tabular}{|c|c|c|c|}
\hline Items & Size & Weight & Value \\
\hline Clothing/shoes & \multirow{3}{*}{ Small } & \multirow{3}{*}{ Light } & \multirow{3}{*}{ Low } \\
\hline Audio-visual products & & & \\
\hline Health \& beauty items & & & \\
\hline General merchandise & \multirow{2}{*}{ Medium } & \multirow{2}{*}{ Medium } & \multirow{2}{*}{ Low } \\
\hline Groceries & & & \\
\hline Computer equipment & Medium & Medium & Medium \\
\hline $\begin{array}{l}\text { Communication devices and other digital } \\
\text { products }\end{array}$ & Small & Light & Medium \\
\hline White goods & Large & Heavy & High \\
\hline Books & Small & Medium & Low \\
\hline
\end{tabular}

Source: Author's analysis.

The determination of the average size and weight ranges of the products is based on packaging advice provided by DHL Size and Price Guide (DHL n.d.). Accordingly, the product can be classified as small if it can fit into a $337 \times 322$ x 180 millimetre (mm) box, medium if it can fit into a 481 x 404 x $389 \mathrm{~mm}$ box and large if it cannot fit into a $481 \times 404 \times 389 \mathrm{~mm}$ box. The product could be classified as light if it weighs less than five kilograms (kg), medium-weight if it weighs between five and $20 \mathrm{~kg}$ and heavy if it weighs more than $20 \mathrm{~kg}$.

As for the numerical range of monetary values of the products, after an investigation of the price ranges for the listed products, a price range of $¥ 100$ 500 ( AUD 17.5-88) for low-value products, Ұ 500-2000 ( AUD 88-500) for medium-value products, and $¥ 2000(\sim$ AUD 500) and higher has been assumed for high-value products.

For simplicity of calculation, the upper weight limits and the mean values of the price range were used. For heavy and expensive products, i.e. white goods, an average weight of $40 \mathrm{~kg}$ and a value of $¥ 6000$ ( AUD 1050) was assumed, based on available data (City of York Council 2013).

\section{Three Logistics Chain Models}

A logistics life cycle assessment (LCA) is conducted for each type of product to streamline the components of the logistics chains in both traditional retailing and e-commerce models. Based on the LCA, three logistics chain models are proposed for the listed products. 


\section{Logistics Chain Model for Regular Products (the Generic Logistics Chain)}

All the listed products, except white goods and groceries, fit into the logistics chain model as depicted in Figure 1. The products in the two retailing models begin at the manufacturer, from where they are later shipped to the wholesaler's warehouse. After the wholesale warehousing stage, the logistics chain in the two retailing models begin to separate. In the traditional retailing model, on receiving the order from the retailer, the products are transported to either the retailer's warehouse or directly to the retail store, and the customer must go to the retail store to pick up the product. In the e-commerce model, the customer places an online order at home. The online retailer receives the order through the data centre of the e-commerce platform and the product is dispatched from the wholesale warehouse to the final distribution centre. Here the product is collected and sorted for last-mile delivery, with a possible stop at the online retailer's secondary warehousing facility. The e-commerce logistics chain concludes with last-mile delivery to the end customer.

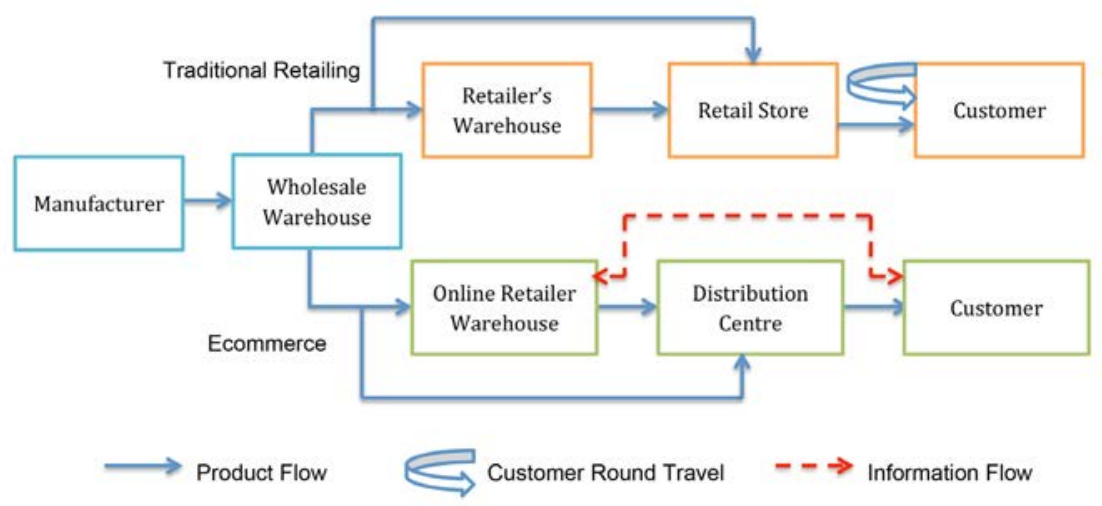

Figure 1: Logistics Chain Model for Large-Sized Products (White Goods)

Source: Author's own work. 
Figure 2 depicts the logistics chain for large-sized products, such as white goods. The logistics link from the manufacturer to the wholesale warehouse is similar to that for regular products. For both traditional retailing and e-commerce models, however, a secondary warehousing stage at the retailers is necessary, since the lead time taken for the large-sized products to be delivered to the retailer is usually longer. The product flow separates after the secondary warehousing stage. In the traditional retailing model, the products are delivered to the retail store and the customer travels to the store to purchase the product. The final delivery of the product to the customer is made by the retailer. In the e-commerce model, the customer places the order online. On the order's arrival, the online retailer dispatches the product from its warehouse. After going through several distribution centres, the product reaches the final local distribution centre and the last-mile delivery of the product is made to the customer.

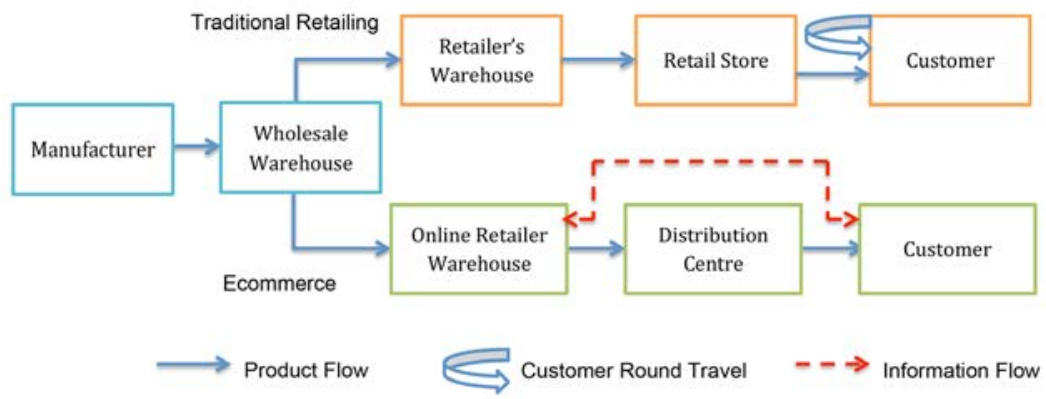

Figure 2: Logistics Chain Model for Grocery Products

Source: Author's own work.

Figure 3 depicts the logistics chain for grocery products. As grocery products are often perishable, it is not realistic for a customer to order the products from a non-local e-commerce company. Most of online grocery retailers are multichannel players; that is, they own retail stores and at the same time they are able to take online orders and deliver the groceries to their customers. The only difference between traditional retailing and e-commerce models for grocery products is in the final logistical link, which is fulfilled by customer travel in the traditional retailing model, versus a last-mile delivery by the retailer in the e-commerce model. 


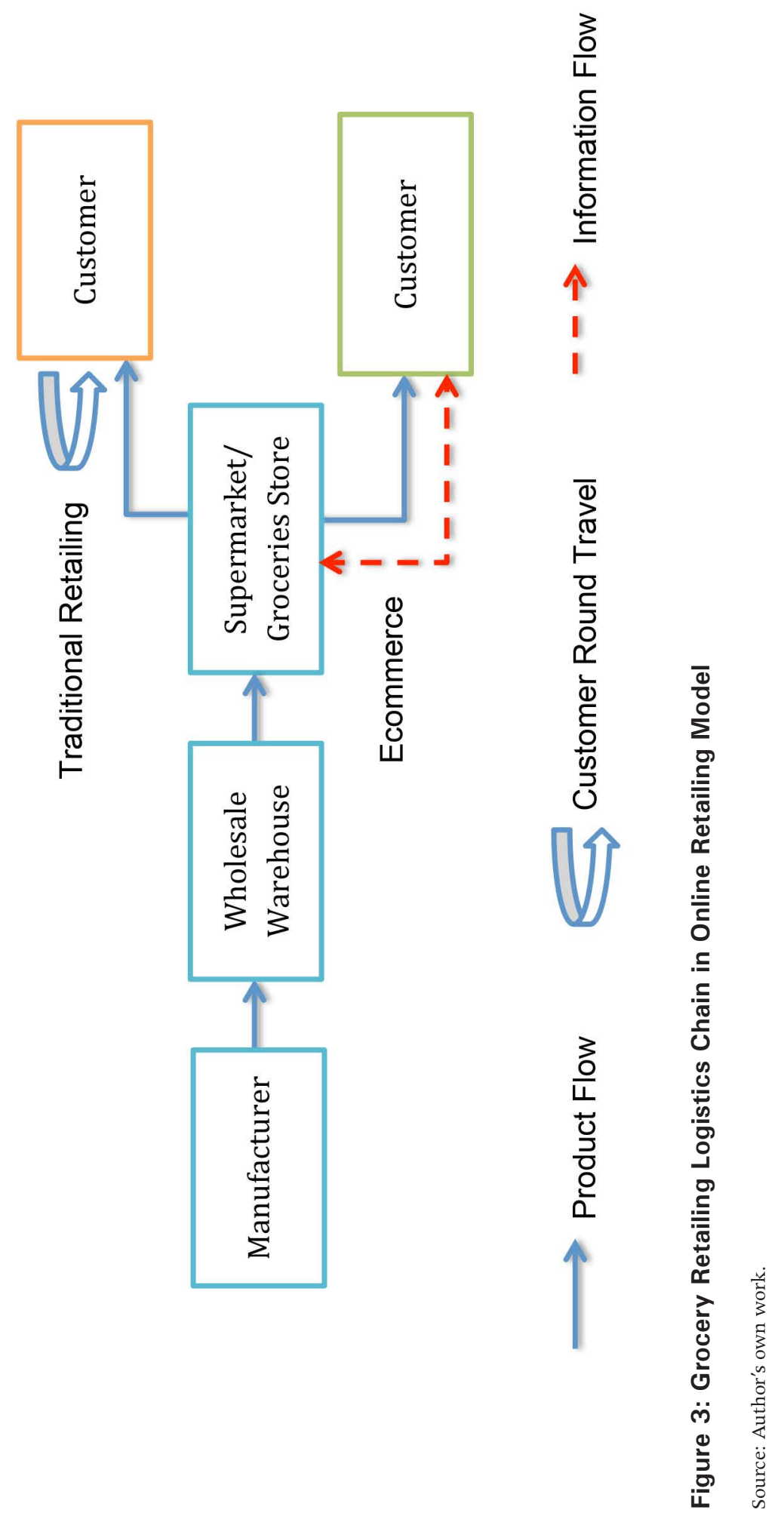


The three logistics models proposed above illustrate that the initial stages of the logistics chains for both retailing models are very similar. Thus, the energy consumption at these initial stages is assumed to be similar and can be excluded from the comparative study. It is hard to draw a comparison between the energy consumption of the two secondary warehousing stages due to insufficient information; hence, we assume that energy consumption at the retailer's warehousing facilities is the same for both retailing models and it can be excluded from the comparative study. In the e-commerce model, we also assume that the energy spent on the product in the distribution centre is small and can be ignored for the comparative study, considering the massive amount of goods that the distribution centre needs to process on a daily basis.

For a generic logistics model, differences in energy consumption between transport links are from the distribution stage, customer travel and last-mile delivery. The non-transportation energy consumption differences are from home and data centre energy usage, and additional packaging materials in the e-commerce model and the retail store in the traditional retailing model. For large-sized products, last-mile delivery is excluded from the scope of this study as it is made in both retailing models. As the packaging methods are similar in both retailing models for large-sized products, the usage difference is assumed to be small and can be disregarded. The grocery logistics model assumes that the retailers in both models are multi-players and, therefore, the retail store and distribution stages are the same and excluded from the study.

In summary, the logistics links that are considered in this project for the three logistics models are summarised in Table 2. 
The ANU Undergraduate Research Journal

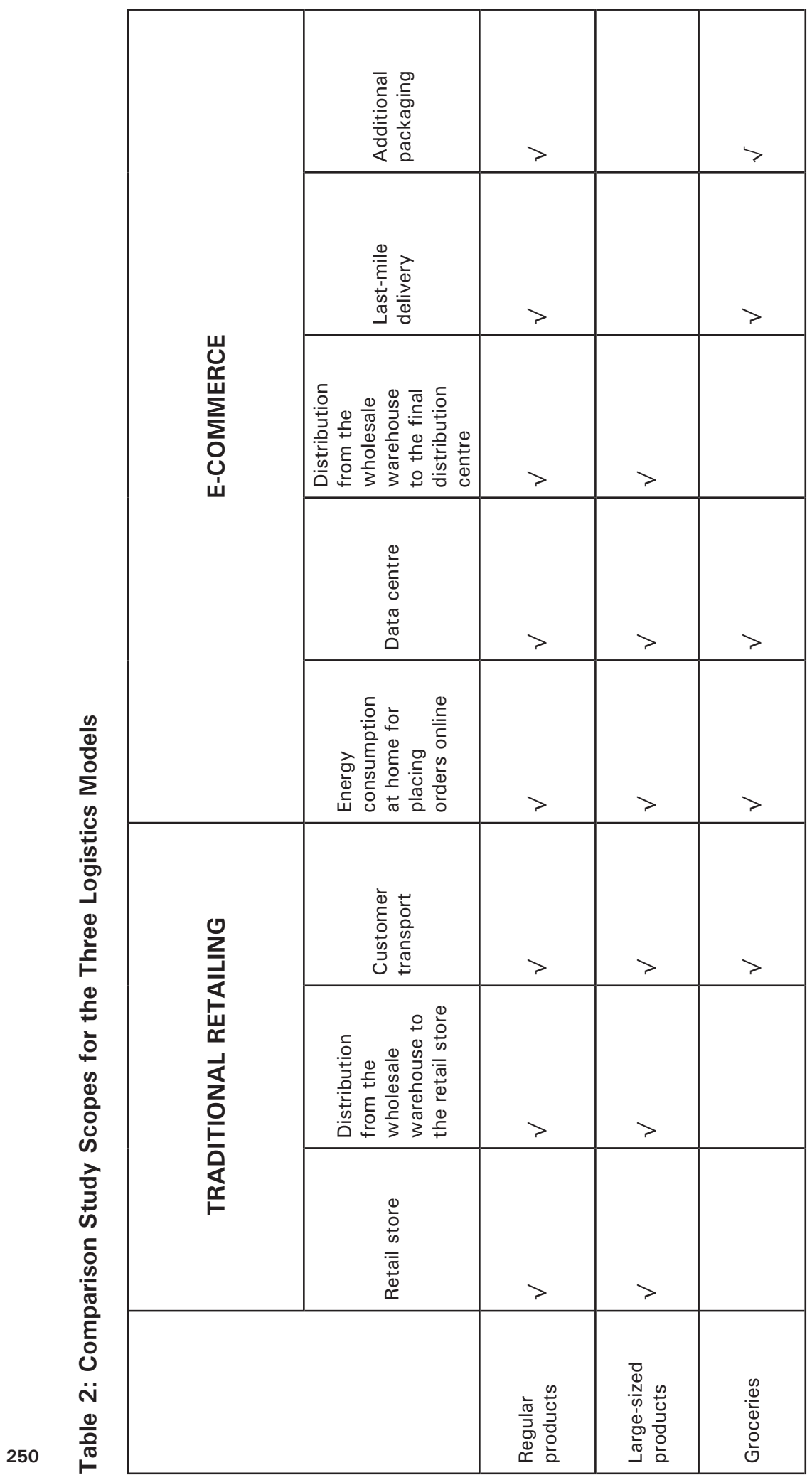

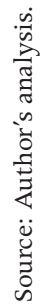




\section{Methodology}

All energy consumption was calculated and presented in megajoules (MJ). Unit abbreviations and the conversion between different energy units are presented in appendices 1 and 2 .

\section{Retail Store Energy Use}

Data on energy consumption of retail stores was obtained from a survey done by China Chain Store \& Franchise Association (CRA 2011). In the survey, it is suggested that the energy consumption of a specialty store is about 70 kilowatt hours (kWh) to $150 \mathrm{kWh}$ for every $¥ 10,000$ ( AUD 1755) of sales generated. The monetary value of the product can be assumed to reflect the energy usage at the retail store. A mean value $110 \mathrm{kWh} / Y 10,000(\sim$ AUD 1755) is used for calculation. The expression for retail store energy use is shown as (the result is converted into $\mathrm{MJ}$ ):

$E_{\text {retail store }}=P_{\text {unit }} / Y 10,000 \times 110 \mathrm{kWh} \times 3.6 \mathrm{MJ} / \mathrm{kWh}$

\section{Energy Consumption at Home for Placing Orders Online}

The energy consumption at home for placing orders online comes from four major sectors: computer, lighting, heating/cooling and the data transfer on completing an online transaction (Weber et al. 2008), as shown in the expression:

$E_{\text {home }}=\left(P_{\text {computer }}+P_{\text {lighting }}+P_{\text {heating/cooling }}\right) \times t_{\text {browsing }}+E_{\text {data transfer }}$

Data on lighting is taken from the Standard for Lighting Design of Buildings specified by the Ministry of Housing and Urban-Rural Development of China (MOHURD), which suggests that the standard domestic lighting power be seven watts per square metre $\left(\mathrm{W} / \mathrm{m}^{2}\right)$ (MOHURD 2004). Data on energy use of home climate control systems is taken from China Building Energy Efficiency Development Report, which suggests that the air-conditioning energy consumption for household climate control in 2004 was $2.7 \mathrm{kWh} / \mathrm{m}^{2}$ (Tsinghua University 2009). To convert the annual energy use into power, we assumed a usage pattern for air-conditioners of ten hours per day, 365 days per year. The power usage of the climate control system is calculated to be $0.74 \mathrm{~W} / \mathrm{m}^{2}$ (2.7 kWh/m² divided by 3650 hours of annual operating time). From the same report, it is suggested that the average household area per capita in urbanised regions is $17.7 \mathrm{~m}^{2}$ in China, so the power usage of lighting and climate control systems at home are calculated to be $123.9 \mathrm{~W}\left(7 \mathrm{~W} / \mathrm{m}^{2} \times 17.7 \mathrm{~m}^{2}\right)$ and $13.1 \mathrm{~W}$ $\left(0.74 \mathrm{~W} / \mathrm{m}^{2} \times 17.7 \mathrm{~m}^{2}\right)$. 
To calculate computer energy use, energy consumption in both the operation phase and the production phase needs to be considered. Computers are different from other household appliances as 80 per cent of their life cycle energy is consumed during the production phase, while only 20 per cent accounts for the energy consumed during the operation phase (Consciousness 1993). We assumed that the power rating of an average PC is $100 \mathrm{~W}$. As for energy use in the production phase, a study done by Williams (2004) indicated that the production energy of a certain desktop computer is $6400 \mathrm{MJ}$. Assuming the usage pattern for a computer is three hours per day with no standby, 365 days per year, for three years, the equivalent production power of the computer is calculated to be $542 \mathrm{~W}$ ( $6400 \mathrm{MJ}$ divided by the total operating time). Including operating power $(100 \mathrm{~W})$, in total the power rating of a computer is $642 \mathrm{~W}$. The average data usage incurred for completing one online transaction is assumed to be $1 \mathrm{Mb}$ (megabyte). A study done by Taylor and Koomey (2008) suggested that the energy consumption for Internet traffic is $\sim 9-16 \mathrm{kWh} / \mathrm{GB}$ of data. Using the mean value $(12.5 \mathrm{kWh} / \mathrm{GB})$, the network energy consumption for an online transaction with $1 \mathrm{Mb}$ of data transfer is calculated to be $0.045 \mathrm{MJ}$.

The time spent on placing an online order is closely related to the monetary value of the product. It is suggested that customers dwell on purchasing decisions for longer if the products are in the high price range (Greenleaf \& Lehmann 1995). For this study the time spent placing an online order to buy products with low, medium and high value is assumed to be 30,45 and 60 minutes respectively.

\section{Data Centre Energy Usage}

To calculate energy use at the data centre, firstly the power usage effectiveness (PUE) factor is introduced as a measure of how efficiently the ICT facilities in the data centre extract energy from the total energy input of the data centre.

$P U E=E_{\text {total data centre }} / E_{I C T \text { facilities }}$

Accordingly, if PUE and the energy usage of ICT facilities are known, the total energy used in the data centre can be calculated. Dividing the total energy usage by the total number of transactions within the same time frame, the data centre energy usage for completing one transaction can be calculated, as shown in expression:

$E_{\text {data center }}=1 / N_{\text {total tranctions }} \times P U E \times E_{\text {ICT facilities }}$

Energy consumption at the data centre is independent of product types. Online retailers are assumed to be operating on Taobao.com, which is the biggest e-commerce platform in China. A general PUE value of 2.5 in China and a total annual energy consumption of the ICT facilities at the data centre of Taobao.com 
of 78840 megawatt hours (MWh) was used (Wang \& Liu 2012). The number of daily transactions made on Taobao.com is 8 million (iResearch 2012). As a result, the energy usage for processing one transaction at the data centre is $0.2 \mathrm{MJ}$.

\section{Distribution}

The distribution stage refers in the traditional retailing model to the transportation of the product from the wholesaler's warehouse to the retail store, and in the e-commerce model, to the final local distribution centre. With no better information available, the distribution distances in the two retailing modes are assumed to be similar. For calculation purposes, the distribution distances are estimated to be 1000 kilometres $(\mathrm{km})$, which is equal to the distance between Beijing and Shanghai.

The transportation method during distribution is assumed to be determined by the size and weight of the product. For small- to medium-sized and light- to medium-weight products, both ground delivery and airfreight are applicable. For large-sized and heavy products, however, ground can be the only option as the product might exceed the size limit of air transportation, or this option is not cost-effective. Transportation in the traditional retailing model is assumed to have been completed with 100 per cent ground delivery via medium truck. For the e-commerce model, small- and medium-sized products are assumed to be transported between the local logistics facilities (from the wholesale warehouse to the despatch air hub, from the arrival air hub to final distribution centre) via light truck for $200 \mathrm{~km}$, and between the regional logistics facilities (from the despatch air hub to the arrival air hub) via airfreight for $800 \mathrm{~km}$. For large-sized products, e.g., white goods, the distribution link is assumed to be completed with 100 per cent of ground delivery via medium truck in the e-commerce model. The energy intensities of the transportation methods mentioned above are listed in Table 3.

Table 3: Energy Intensity and Load Capacity of Transportation Methods

\begin{tabular}{|l|l|l|l|}
\hline $\begin{array}{l}\text { Transportation } \\
\text { method }\end{array}$ & Load capacity & Energy intensity (e) & Fuel \\
\hline Light truck & 5 tonnes & $\begin{array}{l}24.2 \text { litres (L) of fuel } / 100 \\
\mathrm{~km}\end{array}$ & Diesel \\
\hline Medium truck & 10 tonnes & $27.6 \mathrm{~L}$ of fuel $/ 100 \mathrm{~km}$ & Diesel \\
\hline Air carrier & N/A & $22.6 \mathrm{MJ} / \mathrm{t} \cdot \mathrm{km}$ & Jet Fuel \\
\hline
\end{tabular}

Source: Jia et al. 2010; Wu 2007.

To calculate the energy consumption dedicated to transporting one unit of a product, the weight ratio of one unit of the product to the truckload is required. 
For ground delivery, the truck loading factor (LF) was taken into consideration, which is defined by the ratio of the weight (or volume) carried by the vehicle times the distance travelled by the weight (or volume) capacity of the vehicle times the distance travelled (Williams 2002). In China, the loading factor of trucks is around 60 per cent (Pan n.d.). Thus the energy use for transporting one unit of a product can be calculated using the following expressions, where the density of diesel $(\rho)$ is $0.85 \mathrm{~kg} / \mathrm{L}$ and the high heat value (HHV) of diesel is $42652 \mathrm{~kJ} / \mathrm{kg}$ :

$$
\begin{gathered}
E_{\text {ground }}=m_{\text {unit }} / m_{\text {load capacity }} \times L F \times S_{\text {distribution distance }} \times e_{\text {truck }} \times \rho_{\text {diesel }} \times H H V_{\text {diesel }} \\
E_{\text {air }}=m_{\text {unit }} \times S_{\text {distribution distance }} \times e_{\text {air }}
\end{gathered}
$$

\section{Customer transport}

In the traditional retailing model, the distance customers are willing to travel is dependent on the type of product they are going to purchase, as shown in Table 4. Customers also choose the type of transportation based on round-trip shopping distance. Table 5 shows the percentage of customers choosing different types of transportation for different distances. Notice that the sum of percentage under each transportation method for a travel distance does not necessarily result in 100 per cent, as the customers might use multiple transportation methods for a single trip. Also, the customer might purchase more than one product in a single trip. The percentage data in Table 5 can be translated into the percentage of the travel distance covered by a certain transportation method. The energy intensity for each transportation method is summarised in Table 6. To calculate the customer transport energy usage dedicated to buying one unit of a product, a multi-purpose factor (MF) of 0.5 for a shopping trip is assumed, indicating that 50 per cent of the shopping trip energy is used for buying one unit of the product. Frequently purchased products are classified in terms of product types in Table 7. The expression for calculating the energy consumption at the customer transportation stage is shown below, where $\mathrm{f}$ stands for the percentage of the shopping trip covered by a certain transportation method, and e stands for the energy intensity of that transportation method:

$E_{\text {customer transport }}=\sum(\mathrm{f} \times \mathrm{e}) \times S_{\text {shopping distance }} \times M F$ 
Table 4: Customer Transport Distance for Each Type of Product

\begin{tabular}{|l|l|l|}
\hline Product type & Customer travel distance & $\begin{array}{l}\text { Round trip } \\
\text { distance }\end{array}$ \\
\hline Furniture \& electronics & $5.3 \mathrm{~km}$ & $10.6 \mathrm{~km}$ \\
\hline Necessities & $1.9 \mathrm{~km}$ & $3.8 \mathrm{~km}$ \\
\hline Garments & $6.5 \mathrm{~km}$ & $13 \mathrm{~km}$ \\
\hline Groceries & $0.9 \mathrm{~km}$ & $1.8 \mathrm{~km}$ \\
\hline
\end{tabular}

Source: Chai, Weng \& Shen 2008

Table 5: Percentage of Customers (f) using certain Transportation Methods to the Retail Store - Based on Different Types of Products (Can Also be Interpreted as the Percentage of the Travel Distance (f) Covered by a certain Transportation Method)

\begin{tabular}{|l|l|l|l|l|l|l|}
\hline $\begin{array}{l}\text { Round } \\
\text { trip } \\
\text { distance }\end{array}$ & $f($ Walking $) / \%$ & $f($ Cycling $) / \%$ & $f($ Bus $) / \%$ & $f($ Subway $) / \%$ & $f($ Car $) / \%$ & $f($ Others $) / \%$ \\
\hline $10.6 \mathrm{~km}$ & 0 & 5.10 & 30.37 & 12.21 & 61.26 & 0.86 \\
\hline $3.8 \mathrm{~km}$ & 4.50 & 30.04 & 30.51 & 0.81 & 30.17 & 2.33 \\
\hline $13 \mathrm{~km}$ & 0 & 5.10 & 30.37 & 12.21 & 61.26 & 0.86 \\
\hline $1.8 \mathrm{~km}$ & 56.41 & 29.08 & 3.05 & 0.02 & 7.60 & 3.54 \\
\hline
\end{tabular}

Source: Huang, Song \& Tao 2008.

Table 6: Energy Intensity of Customer Transportation Methods

\begin{tabular}{|l|l|}
\hline Transportation method & Energy intensity (e) \\
\hline Car & $4.0 \mathrm{MJ} /$ vehicle $^{*} \mathrm{~km}$ \\
\hline Bus & $651 \mathrm{~kJ} /$ person ${ }^{*} \mathrm{~km}$ \\
\hline Subway & $117 \mathrm{~kJ} /$ person ${ }^{*} \mathrm{~km}$ \\
\hline Walking/cycling & 0 \\
\hline
\end{tabular}

Source: Ma 2004; Wu 2007. 
The ANU Undergraduate Research Journal

Table 7: Summary of Product Types

\begin{tabular}{|l|l|l|}
\hline Product type & Items & Round trip distance \\
\hline Furniture \& electronics & $\begin{array}{l}\text { White goods } \\
\text { Computer equipment } \\
\text { Communication devices } \\
\text { Other digital products } \\
\text { Audio-visual products }\end{array}$ & $10.6 \mathrm{~km}$ \\
\hline Necessities & $\begin{array}{l}\text { Books } \\
\text { Health and beauty items } \\
\text { General merchandise }\end{array}$ & $3.8 \mathrm{~km}$ \\
\hline Garments & Clothing/shoes & $13 \mathrm{~km}$ \\
\hline Groceries & Groceries & $1.8 \mathrm{~km}$ \\
\hline
\end{tabular}

Source: Author's analysis.

\section{Last-Mile Delivery}

For the last leg of the logistics chain in the e-commerce model, the delivery distance is assumed to be $100 \mathrm{~km}$ between the final distribution centre and the customer and the transportation to be via light van, with the energy intensity shown in Table 8. Similar to the calculation of distribution energy use, the weight of the product influences the energy consumption at this stage. A loading factor (LP) of 60 per cent was applied. With the representative weight specified for light, medium and heavy products, the last-mile delivery energy consumption can be calculated using the expression:

$E_{\text {Last mile }}=m_{\text {item }} / m_{\text {load capacity }} \times L P \times S_{\text {delivery distance }} \times e_{\text {transportation }}$

Table 8: Energy Intensities of Last-Mile Delivery Transportation Methods

\begin{tabular}{|l|l|l|l|}
\hline $\begin{array}{l}\text { Transportation } \\
\text { method }\end{array}$ & $\begin{array}{l}\text { Load } \\
\text { capacity }\end{array}$ & Energy intensity & Fuel \\
\hline Light van & 1 ton & $12.5 \mathrm{~L}$ of fuel $/ 100 \mathrm{~km}$ & $\begin{array}{l}\text { Gasoline } \\
(=0.72 \mathrm{~kg} / \mathrm{L} \\
\mathrm{HHV}=44000 \mathrm{~kJ} / \mathrm{kg})\end{array}$ \\
\hline
\end{tabular}

Source: McKinnon n.d; Wu 2007. 


\section{Additional packaging}

In the e-commerce model, in order to prevent damage to the products during shipment, more packaging materials are used than in the traditional retailing model. To calculate the energy use difference resulting from additional packaging, the usage difference is assumed to be that of extra corrugated boxes, while assuming that the usage difference of other packaging materials is negligible between the two retailing models. As discussed before, the additional packaging of large-sized products in e-commerce model can be neglected.

The type of corrugated box is assumed to be ECT $44 \mathrm{C}$ and the size of the corrugated boxes used for small- and medium-sized products are assumed to be $337 \times 322 \times 180 \mathrm{~mm}$ and $481 \times 404 \times 389 \mathrm{~mm}$, as suggested by DHL (DHL n.d.). The weight of the corrugated cardboard boxes with a known size can be calculated by using the packaging weight tool (Packaging Calculator 2010): 498 grams ( $\mathrm{g}$ ) for a small box and $1003 \mathrm{~g}$ for a medium box. The energy intensity data of the corrugated cardboard is taken from the US Environmental Protection Agency's (EPA) Waste Action and Reduction Model (WARM) (2012). It is suggested that the 30-year life cycle energy of producing and using one $\mathrm{kg}$ of corrugated cardboard material is $28.3 \mathrm{MJ}$. With these data, the energy for the use of additional material can be calculated with the expression:

$E_{\text {add packaging }}=e_{\text {corrugated }} \times m_{\text {box }}$

\section{Results}

Figures 4 and 5 show the results of the previous calculations, and allow for a comparison of the energy consumption differences between the traditional retailing and the e-commerce models.

For traditional retailing, the logistics link with dominant energy usage varies across different types of product: it is the retail store for white goods $(61.7 \%)$, computer equipment $(51.0 \%)$, communication devices $(68.8 \%)$ and health and beauty products $(52.0 \%)$; the distribution stage for general merchandise and books (69.6\% for both); and, customer transport for clothing and shoes $(46.1 \%)$, and groceries $(100 \%)$. For almost all types of products, logistics energy usage for traditional retailing is relatively low, ranging from $0.3 \mathrm{MJ}$ (groceries) to 97 MJ (computer equipment), except for white goods, which results in a stunning amount of energy consumption (385.1 MJ) (Fig. 4). 


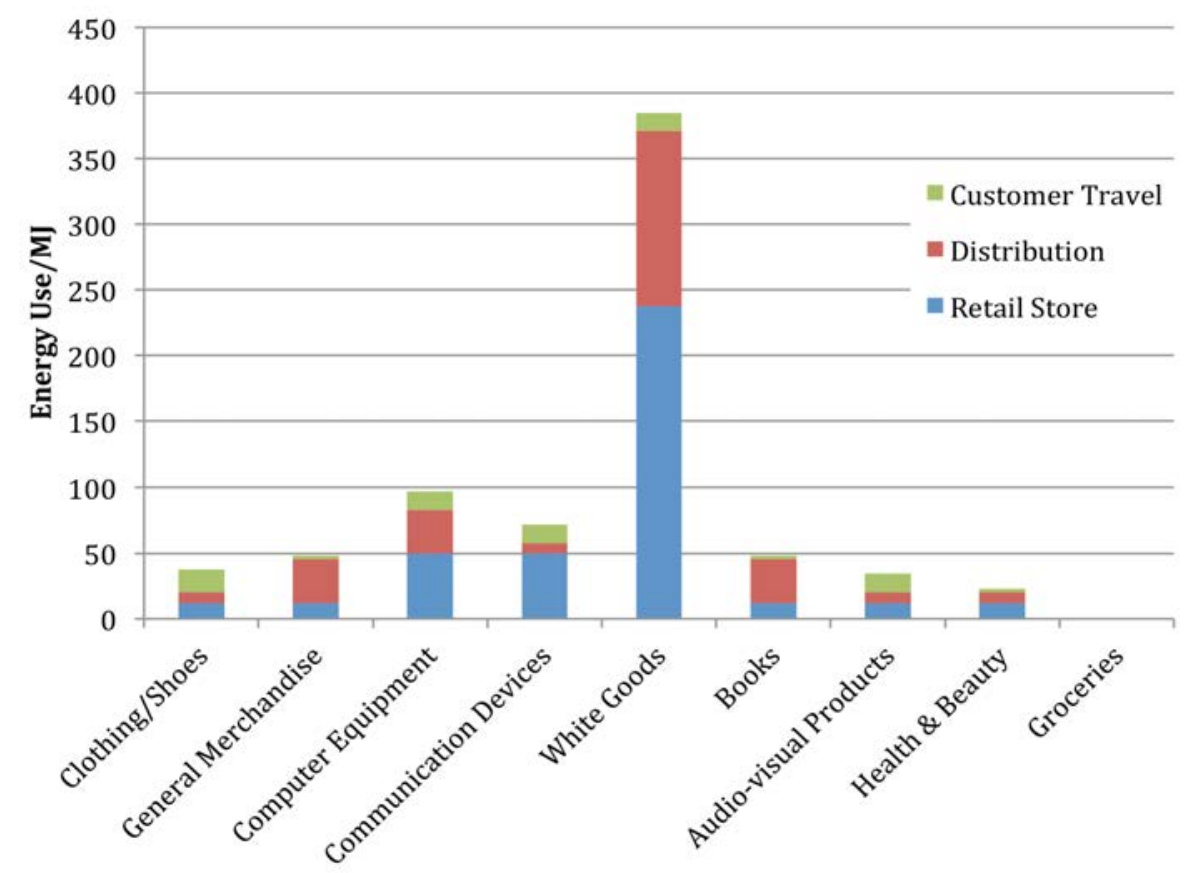

Figure 4: Energy Consumption in Traditional Retailing Logistics Model by Sections

\section{Source: Author's analysis.}

For the e-commerce model, Figure 5 clearly illustrates that the distribution stage is the logistics link with dominant energy usage for almost all types of product, except for grocery products, whose distribution stages are beyond the scope of this comparison. This dominance can be explained by the high-energy intensity of air transportation, and the assumption of the high percentage of air transportation adopted in the distribution stage for the e-commerce model. 


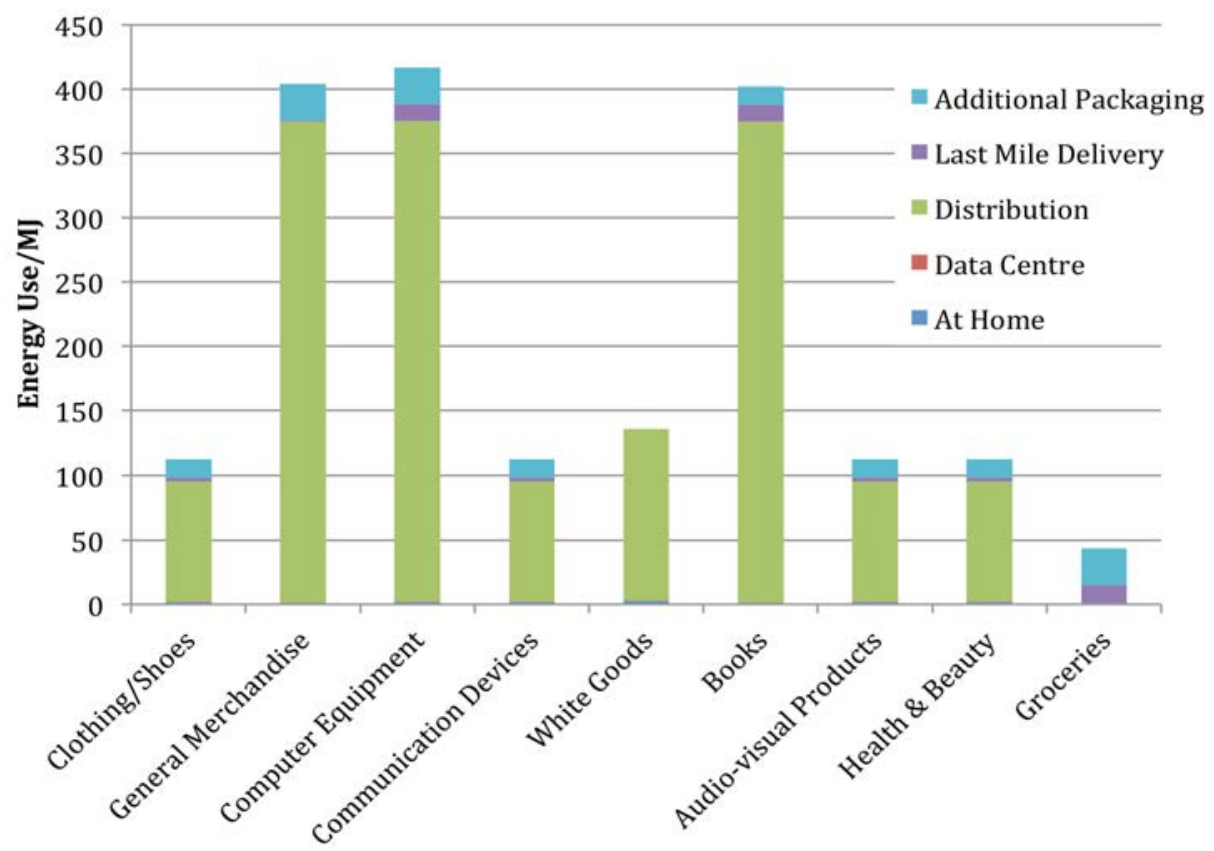

Figure 5: Energy Consumption in E-commerce Model by Sections

Source: Author's analysis.

A comparison of energy consumption of the logistics chain in the two retailing models is shown in Figure 6. Given the high-energy consumption for heavy product distribution via airfreight, unsurprisingly, the e-commerce model consumes more energy than the traditional retailing model in the logistics chain for all product types, except for white goods. For white goods, the e-commerce model is absolutely in a leading position in terms of energy consumption, as the e-commerce model eliminates the heavy energy-consuming links of the retail store and customer travel in the logistics chain. 


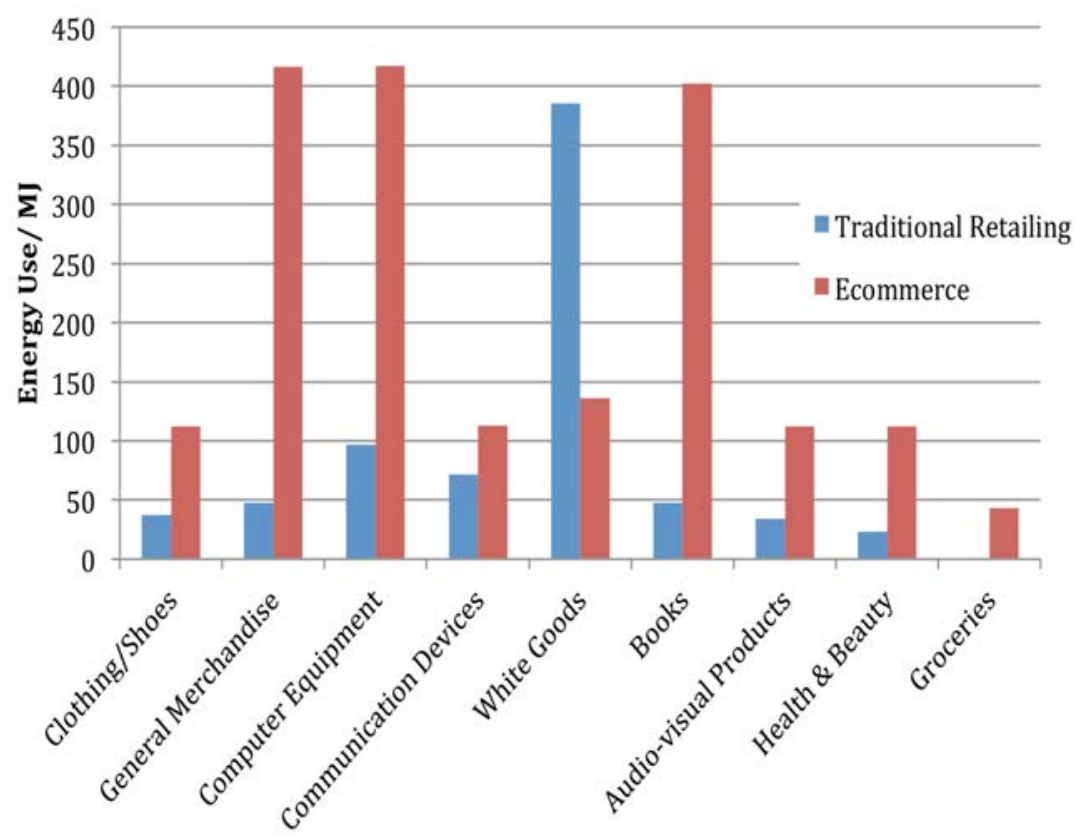

Figure 6: Comparing Energy Consumption in the Traditional Retailing and E-commerce Models

Source: Author's analysis.

\section{Sensitivity Analysis}

In this section, two sensitivity analyses are conducted between distribution energy consumption and mixed air and ground transportation, as well as the distribution distance in the e-commerce model.

In the section on Distribution, transportation between the regional logistics centres in the e-commerce model was assumed to be completed via air freight. This results in a mix of 80 per cent air and 20 per cent ground transportation for the distribution link, which can serve as the worst case scenario for the energy consumption calculation. In a more generic case, ground transportation might also be involved in the distribution link between regional logistics centres in the e-commerce model, raising the share of the ground transport, as shown in studies: 12 per cent air and 88 per cent ground (Weber et al. 2008) and 50 per 
cent air and 50 per cent ground (Matthews et al. 2001). According to the major Chinese logistics companies, around ten per cent of goods are distributed via air. To reflect a more generic case, a mix of 10 per cent air and 90 per cent ground (with medium-duty truck) transportation is assumed in the e-commerce model for the sensitivity analysis.

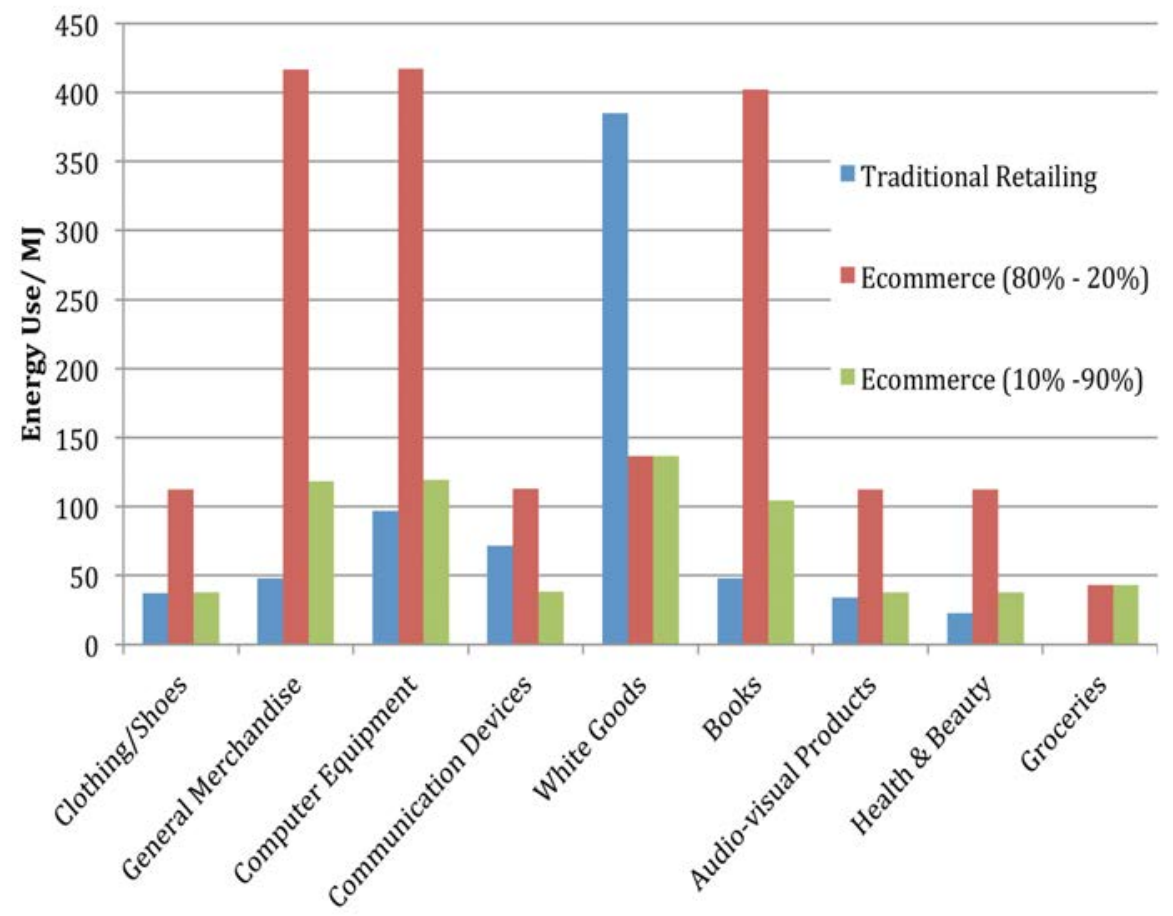

Figure 7: Energy Consumption Comparison between Traditional Retailing Model, E-commerce Model with $\mathbf{8 0} \%$ Air and $20 \%$ Ground Transportation, and $10 \%$ Air and $90 \%$ Ground Transportation

Source: Author's analysis.

As Figure 7 suggests, after decreasing the percentage of air transportation in the e-commerce model, the total e-commerce energy consumption shrinks by about 30 per cent to 60 per cent for most products. Although previously the e-commerce model for clothing and shoes, computer equipment, audio-visual products and health and beauty products consumed significantly more energy than the traditional retailing model, it has now become competitive with the traditional retailing model in terms of energy consumption. For communication devices, the e-commerce model consumes less energy than the traditional retailing model. 
Another special feature for retailing in China is that many manufacturers and wholesalers, especially in south-east China, are located nearby to the consumers' market. So the distribution distance between the wholesaler and the consumer may be smaller than assumed. For the second sensitivity study, a distribution distance of $200 \mathrm{~km}$ was assumed for the two retailing models. For this distance, air transportation would be unrealistic and the transportation methods for distribution in the two retailing models were assumed to be the same and were therefore excluded. The results are shown in Figure 8.

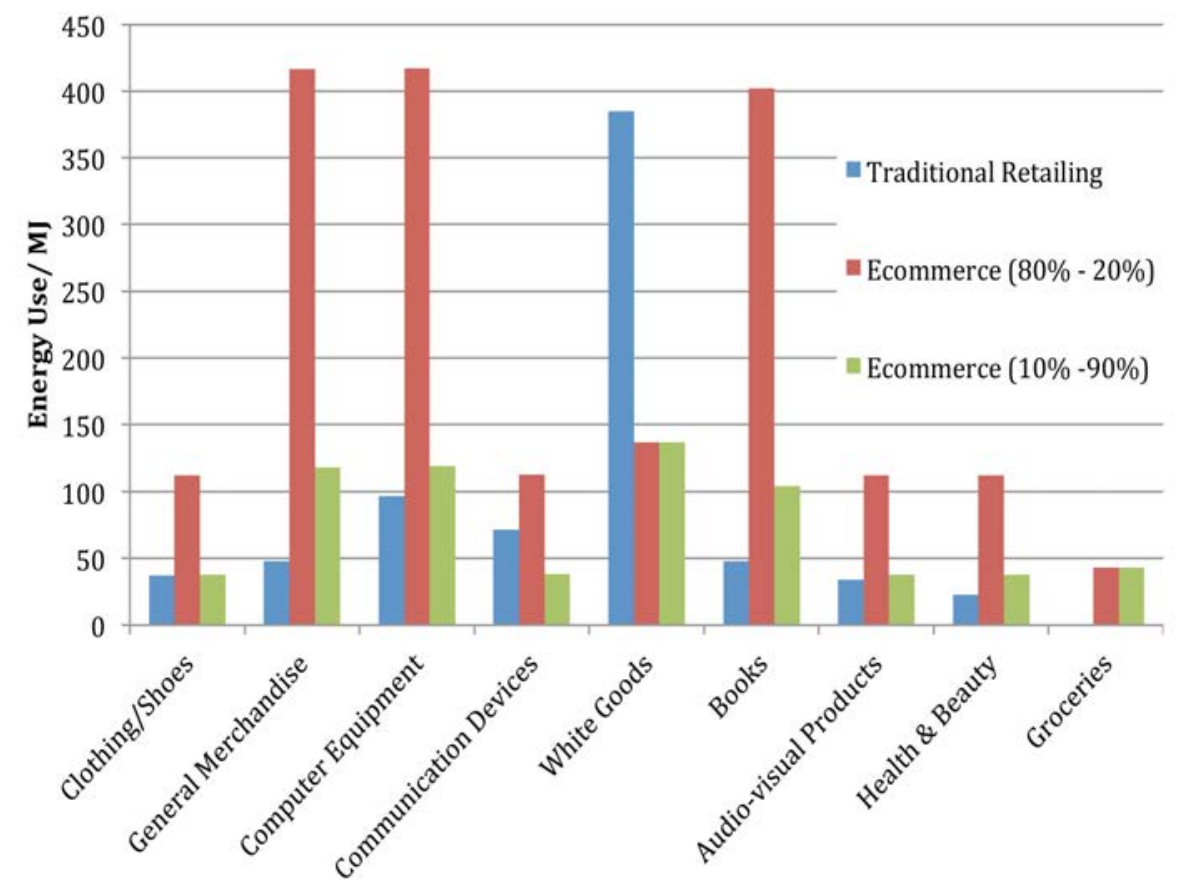

Figure 8: Energy Use in Logistics Chains of Traditional Retailing, E-commerce with Distribution Distance of 200 km

Source: Author's analysis.

As the distribution distance is shortened to $200 \mathrm{~km}$, the advantage of e-commerce is further emphasised for products such as clothing and shoes, computer equipment, communication devices, audio-visual products and health and beauty products. For general merchandise and grocery products, the high-energy consumption for last-mile delivery and additional packaging has prevented the e-commerce model from performing better than the traditional retailing model in terms of energy use. For white goods, the lower energy consumption of the e-commerce model remains. 
From these two sensitivity analyses, we see that the energy consumption of the logistics chain in the e-commerce model is dominated by energy consumption in the distribution link, as the percentage of airfreight and the distribution distance can both greatly influence the total energy consumed in the distribution link. The high percentage of air transportation impairs the competiveness of e-commerce against traditional retailing in terms of energy consumption. For a short logistics chain that can be locally completed, however, e-commerce could be more energy-efficient for certain products, as the energy-consuming stages, including the retail store and customer transport, in traditional retailing are replaced with last-mile delivery with less energy consumption. The good performance of e-commerce's energy-saving features in the short distribution distance scenario suggests the potential of e-commerce to be an effective tool to promote the energy efficiency for local economy activities. By incorporating e-commerce into the local economy structure, further energy efficiency and environmental benefits can be expected.

\section{Conclusion and Further Work}

Three logistics chain models were generalised for traditional and e-commerce retailing of products that are often purchased online and the energy consumption at each stage of the logistics chain was assessed against one of the product features in both retailing models. The energy consumptions in both retailing models were compared for each type of product. We found that the distribution stage in the e-commerce model is of the most importance, as its energy consumption is sensitive to a mix of air-ground transportation and distribution distance. Thus the competiveness of e-commerce against traditional retailing in terms of energy consumption is strongly related to conditions at the distribution stage. Varying results for the energy consumption of the two retailing models could be obtained for different types of products.

Further work can be done to improve the descriptive correlation between the product features and the energy consumed throughout the logistics chain, for example by incorporating more product features or specifying more levels to one product feature when calculating the energy consumptions throughout the logistics chain. Also, the methodology proposed in this project can be used to analyse the differences in energy efficiency between the traditional retailing and e-commerce for other countries or regions. As e-commerce increases during the ongoing ICT revolution, understanding these differences will assume even greater importance in the future. 
The ANU Undergraduate Research Journal

\section{Acknowledgements}

I would like to thank Dr Matthew Doolan for his advice, encouragement and help in finishing this paper. I would also like to thank Dr Jane Golley and Ms Yimeng Jiang for reviewing my paper.

\section{Appendix 1}

Table 9: Unit Abbreviations

\begin{tabular}{|l|l|}
\hline Full name & Abbreviation \\
\hline gigabyte & $\mathrm{GB}$ \\
\hline kilogram & $\mathrm{kg}$ \\
\hline kilometre & $\mathrm{km}$ \\
\hline kilowatt hour & $\mathrm{kWh}$ \\
\hline litre & $\mathrm{L}$ \\
\hline megabyte & $\mathrm{MB}$ \\
\hline megajoule & $\mathrm{MJ}$ \\
\hline megawatt hour & $\mathrm{MWh}$ \\
\hline millimetre & $\mathrm{mm}$ \\
\hline tonne & $\mathrm{t}$ \\
\hline watts & $\mathrm{W}$ \\
\hline yuan (Chinese currency) & $¥$ \\
\hline
\end{tabular}

\section{Appendix 2}

\section{Conversion Between Energy Units}

$1 \mathrm{kWh}=3.6 \mathrm{MJ}$

$1 \mathrm{MWh}=3600 \mathrm{MJ}$ 


\section{Bibliography}

Abukhader, S 2003, The Environmental Implications of Electronic Commerce: The Assessment Approach Problem, Department of Design Sciences, Lund University, Sweden.

Australian Communications and Media Authority (ACMA) 2010, Australia in the Digital Economy: Consumer Engagement in E-commerce, viewed 30 January 2012, <http://www.acma.gov.au/webwr/_assets/main/lib310665/ aust_in_digital_economy-consumer_engagement_with_e-commerce.pdf > .

Berger, AJ 2003, 'E-commerce and Supply Chains - Breaking Down the Boundaries', Gower Handbook of Supply Chain Management.

Chai, Y, Weng, G \& Shen, J 2008, 'A Study on Commercial Structure of Shanghai Based on Residents' Shopping Behavior', Geographical Research, vol. 4.

China Chain Store \& Franchise Association (CRA) 2011, Energy Conservation of Chinese Retailing Industry — The Green Book, Chinese Retail Association. China Internet Network Information Centre (CNNIC) 2013, Gao Shuang: The Comparison of Online Purchases between the Chinese and British Consumers, viewed 28 August 2013, <http://www.cnnic.cn/hlwfzyj/fxszl/ fxswz/201305/t20130517_39655.htm>.

City of York Council, 'Set of Average Weights for Furniture, Appliances and Other Items', Furniture Re-use Network, viewed 25 May 2013, <http:// democracy.york.gov.uk/documents/s2569/Annex\%20Ac\%20Recycling\% 20 and $\% 20$ Re-use $\% 20$ Scrutiny.pdf $>$.

Consciousness, E 1993, A Strategic Competitiveness Issue for the Electronics and Computer Industry, Microelectronics and Computer Technology Corporation, Austin.

DHL, 'Size and Weight Guide', viewed 28 May 2013, <http://www.dhlservicepoint. co.uk/sizeprice.htm>.

Greenleaf, EA \& Lehmann, DR 1995, 'Reasons for Sustainable Delay in Consumer Decision Making', Journal of Consumer Research, vol. 22, no. 2, pp. 186-99.

Huang, S, Song, R \& Tao, Y 2008, 'Behavior of Urban Residents Travel Mode Choosing and Influencing Factors - Taking Beijing as an Example', Communication Standardization, vol. 191, no. 9, pp. 124-28.

iResearch 2012, 'Annual Sales of Taobao and Tmall have Exceeded Trillion', viewed 28 August 2013, <http://ec.iresearch.cn/shopping/20121203/188112.shtml>. 
The ANU Undergraduate Research Journal

Jia, S, Mao, B, Liu, S \& Sun, Q 2010, 'Calculation and Analysis of Transportation Energy Consumption Level in China', Journal of Transportation Systems Engineering and Information Technology, vol. 10, no. 1, pp. 22-27.

Ma, X 2004, 'Analysis of the Energy Exhaustion of the Urban Rail Transit Vehicles', The Retail Report, no. 6, pp. 21-23.

Matthews, HS, Hendrickson, CT \& Soh, DL 2001, Environmental and Economic Effects of E-Tail: A Case Study of Book Publishing and Retail Logistics, Transportation Research Record 1763, no.1, pp. 6-12.

McKinnon, A, $\mathrm{CO}_{2}$ Emissions from Freight Transport: An Analysis of UK Data, Logistics Research Centre, Heriot-Watt University, Edinburgh.

Ministry of Housing and Urban-Rural Development of China (MOHURD) 2004, Standard for Lighting Design of Buildings: GB 50034-2004, Ministry of Housing and Urban-Rural Development of China.

Packaging Calculator 2010, viewed 28 May 2013, <http://packagingcalculator.com/>.

Pan. Y, 'Promote the Vehicles' Capacity Factor to Increase the Operational Efficiency of Vehicles', viewed 28 August 2013, <http://www.docin. com/p-100393484.html>.

Redant, Digital Engagement in China: Where Social Becomes Serious, viewed 3 June 2013, <https://www.redant.com/_assets/files/Digital_Engagement_ China.pdf $>$.

Taylor, C \& Koomey, J 2008, 'Estimating Energy Use and Greenhouse Gas Emissions of Internet Advertising', Network.

Tsinghua University 2009, China Building Energy Efficiency Development Report, lst edn, China Architecture \& Building Press.

US Environmental Protection Agency (EPA) 2012, 'Waste Reduction Model' viewed 21 May 2013, <http://epa.gov/epawaste/conserve/tools/warm/index.html>.

Wang, H \& Liu, Q 2012, 'The Comparative Study of Energy Consumption Between E-commerce and Traditional Business', China Information Times, vol. 207, no. 3, pp. 9-13.

Weber, C, Hendrickson, C, Jaramillo, P, Matthews, S, Nagengast, A \& Nealer, R 2008, Life Cycle Comparison of Traditional Retail and E-commerce Logistics for Electronics Products: A Case Study of buy.com, Green Design Institute, Carnegie Mellon University. 
Williams, E 2002, 'Energy Efficiency of b2c E-Commerce in Japan', IEEE International Symposium on Electronics and the Environment, IEEE, pp. 38-43.

2004, 'Energy Intensity of Computer Manufacturing: Hybrid Assessment Combining Process and Economic Input-Output Methods', Environmental Science \& Technology, vol. 38, no. 22, pp. 6166-74.

Wu, W 2007, 'Comparison of Energy Consumption of Traffic and Transportation Between China and the Typical Countries', Sino-Global Energy, vol. 29, no. 10, pp. 19-22. 
This text taken from The ANU Undergraduate Research Journal Volume Five 2013, published 2014 by ANU Press, The Australian National University, Canberra, Australia. 